\title{
Vascular endothelial growth factor-1 as a predictor of unfavorable cardiovascular events in arterial hypertension patients after ischemic stroke
}

\author{
Alexander Berezin ${ }^{1 *}$, Oxana Lisovaya ${ }^{2}$ \\ ${ }^{1}$ State Medical University, Zaporozhye, Ukraine \\ ${ }^{2}$ District Hospital \#6, Zaporozhye, Ukraine
}

Objective: Circulating vascular endothelial growth factor-1 (VEGF-1) is considered as neuroprotective factor with angiopoetic capacity ${ }^{1,2}$. However, interrelationship between VEGF-1 and frequency of recurrent cardiovascular outcomes in hypertensive patients after stroke in long-term follow-up is still uncertain ${ }^{3}$. Aim: To evaluate the relationship between VEGF-1 and risk of recurrent coronary and cerebral ischemic events in arterial hypertension patients after the stroke.

Methods: 102 mild-in-moderate arterial hypertension patients were enrolled to the in study 3 weeks after ischemic stroke and then they were being studied prospectively for 12 months period regarding survival rate and unfavorable clinical outcomes. Circulating VEGF-1 level was determined in the study entry only. Clinical interviews were performed every 3 months during 1 year after blood sampling.

Results: Analysis of obtained outcomes showed that medians of circulating VEGF-1 levels in hypertensive patients after stroke, which demonstrated one, two, three or more cases of recurrent cardiovascular events were $373.80 \mathrm{pg} / \mathrm{ml}$ $(95 \% \mathrm{Cl}=342.90-479.70 \mathrm{pg} / \mathrm{mL}), 539.96 \mathrm{pg} / \mathrm{ml} \quad(95 \% \mathrm{Cl}=$ $444.28-865.56 \mathrm{~g} / \mathrm{mL})$, and $724.66 \mathrm{pg} / \mathrm{mL}(95 \% \mathrm{Cl}=558.72-$ $890.66 \mathrm{pg} / \mathrm{mL}$ ) respectively, and they were significantly higher than that of the persons for whom new clinically relevant cardiovascular outcomes were not documented (Me= $289.28 \mathrm{pg} / \mathrm{mL}, 95 \% \mathrm{Cl}=279.71-345.88 \mathrm{pg} / \mathrm{mL})(\mathrm{P}=0.001$ for all cases). The cutoff point of VEGF-1 with the most optimal predictive value for recurrent cardiovascular events was equal to $403.57 \mathrm{pg} / \mathrm{mL}$ (area under the curve $=0.76$, $95 \% \mathrm{Cl}=0.602-0.917, \mathrm{P}=0.001$, sensitivity $=78.6 \%$ and specificity $=70.0 \%$ respectively). In this case, when circulating
VEGF-1 level was more than $403.57 \mathrm{pg} / \mathrm{ml}$, the number of reported cardiovascular events during one year follow-up was significantly higher in comparison to lower levels of one $(\mathrm{OR}=4.11,95 \% \mathrm{Cl}=2.66-7.28, \mathrm{P}=0.001)$. Kaplan-Meier curves began to divide about 10 weeks after the study entry and achieved a significant difference in 14 weeks. After that a difference in events occurrence between the two patient cohorts with circulating VEGF-1 level less and more 403.57 $\mathrm{pg} / \mathrm{mL}$ continued to deepen.

Conclusion: We found that circulating vascular endothelial growth factor-1 level was an independent predictor of 1 year cumulative cardiovascular events in hypertensive patients after ischemic stroke.

KEYWORDS: vascular endothelial growth factor-1, ischemic stroke, arterial hypertension, unfavorable clinical outcomes, predicted value.

CITATION: Cardiol Croat. 2013;8(9):322.

\footnotetext{
Received: $12^{\text {th }}$ Jul 2013
}

*Address for correspondence: Internal Medicine Department, State Medical University, 26, Mayakovsky av., 69035 Zaporozhye, Ukraine.

Phone: +380612729607

E-mail: dr_berezin@mail.ru

\section{Literature}

1. Zachary I, Mathur A, Yla-Herttuala S, Martin J. Vascular protection: a novel nonangiogenic cardiovascular role for vascular endothelial growth factor. Arterioscler Thromb Vasc Biol. 2000;20:1512-20.

2. Tuttolomondo A, Di Raimondo D, Pecoraro R, Arnao V, Pinto A, Licata G. Inflammation in ischemic stroke subtypes. Curr Pharm Des. 2012;18(28):4289-310.

3. Sun Y, Jin K, Xie L, Childs J, Mao XO, Logvinova A, Greenberg DA. VEGF-induced neuroprotection, neurogenesis, and angiogenesis after focal cerebral ischemia. J Clin Invest. 2003;111:1843-51. 